\title{
Adubação Nitrogenada de Sorgo Avaliada pelo Teor de Clorofila com Método Convencional e por Medidor Portátil
}

Vitor C. M. Barretto, Alex da Silva, José M. G. Beraldo, Mara C. P. Cruz \& Manoel E. Ferreira

Avaliou-se o teor de clorofila por medidor portátil de clorofila (SPAD), em relação ao método analítico, sob doses de nitrogênio, na cultura do sorgo em casa de vegetação. O delineamento experimental usado foi o inteiramente casualizado, com cinco doses de nitrogênio e quatro repetições. O medidor SPAD apresentou alta correlação para teor de nitrogênio total na folha, teor de clorofila (total, a e b), e produção de matéria seca da folha. As doses de 225 e $300 \mathrm{mg} \mathrm{dm}^{-3}$ de $\mathrm{N}$ proporcionaram teores foliares de 13,87 e $17,55 \mathrm{~g} \mathrm{~kg}^{-1}$ respectivamente, porém, estas doses afetaram a produção de matéria seca.

Palavras-chave: Métodos de avaliação; Sorghum bicolor L.; SPAD.

Assessed chlorophyll content for portable chlorophyll meter (SPAD) in relation to analytical method under doses of nitrogen in the culture of sorghum under greenhouse conditions. The experimental design used was the completely randomized design, with five nitrogen doses and four replicates. The SPAD meter showed high correlation to total leaf nitrogen content, chlorophyll content (total, a and b), and leaf dry matter production. The doses of 225 and $300 \mathrm{mg} \mathrm{dm}^{-3}$ of $\mathrm{N}$ foliar provided 13.87 and $17.55 \mathrm{~g}$ $\mathrm{kg}^{-1}$ respectively, however, these doses affected the production of dry matter.

Key words: Methods of assessments;Sorghum bicolor L.; SPAD. 


\section{Introdução}

No Brasil, a cultura do sorgo (Sorghum bicolor L.) vem crescendo cada vez mais, devido à utilização de plantas com potencial genético e também ao manejo da cultura com a aplicação adequada de nutrientes. $\mathrm{O}$ nitrogênio participa da constituição da molécula de clorofila, a avaliação da necessidade de $\mathrm{N}$ pela planta poderia ser determinada pela mensuração indireta do teor de clorofila ${ }^{1}$.

A molécula de clorofila é o pigmento principal na absorção de luz na região do visível, sendo que ela é composta de $6 \%$ de nitrogênio ${ }^{2}$. Plantas sem nitrogênio apresentam menor composição de clorofila, consequentemente, havendo redução da taxa fotossintética, produção de assimilados e acúmulo de massa $\operatorname{seca}^{3,4}$. O manejo da adubação nitrogenada da cultura do sorgo pode ser alcançado por meio de determinações periódicas e precisas do estado nutricional. As determinações das concentrações de nitrogênio na matéria seca de folhas, geralmente, são em condições de laboratório, empregando-se métodos analíticos, demorados e de alto custo ${ }^{5}$, e que requerem destruição de amostras de tecidos e muito trabalho nos processos de extração e quantificação ${ }^{6,7}$.

Em contraposição aos métodos tradicionais, a determinação indireta de clorofila, por meio de medidores portáveis, desponta como mais uma alternativa na diagnose da necessidade de adubação nitrogenada para as culturas, de forma fácil, rápida, e não destrutiva ${ }^{5,6,7,8}$. Por não ser afetada pelo consumo de luxo de nitrogênio, a medida indireta de clorofila, por meio do medidor portátil, tem sido considerada melhor indicadora do nível do nitrogênio na planta do que o próprio teor total do elemento?.

Os índices de clorofila nas folhas correspondem ao teor relativo de clorofila presente na folha obtido pelo medidor portátil de clorofila, esses valores são calculados com base na quantidade de luz transmitida por meio da folha na faixa do vermelho e do infravermelho próximo, por apresentar alta correlação com o conteúdo de $\mathrm{N}$ na folha ${ }^{10}$.

A concentração de clorofila pode indicar a concentração de $\mathrm{N}$ na folha de milho, podendo ser uma determinação mais sensível às variações do suprimento de $\mathrm{N}$ que as determinações do nutriente na matéria seca das folhas $5, \mathrm{o}$ que possibilitaria maior rapidez na deteç̧ão da deficiência de $\mathrm{N}^{11}$. O presente trabalho teve como objetivo avaliar o uso do medidor de clorofila SPAD em relação ao método analítico sob doses de nitrogênio na cultura do sorgo em casa de vegetação.

\section{Material e Métodos}

$\mathrm{O}$ experimento foi conduzido em casa de vegetação utilizando o delineamento experimental inteiramente casualizado, com cinco doses de nitrogênio $(0 ; 75 ; 150 ; 225$ e $330 \mathrm{mg} \mathrm{dm}^{-3}$ ), empregando como fonte de nitrogênio a uréia, e quatro repetições.

O solo utilizado foi coletado a uma profundidade de 0-20 cm, em área de pastagem no município de BorboremaSP, colocado para secar à sombra, destorroado, peneirado em peneira de $4 \mathrm{~mm}$ e homogeneizado. As características químicas do solo foram determinadas antes da instalação do experimento, segundo metodologia proposta por Raij ${ }^{15}$. Os valores obtidos foram: $\mathrm{P}$ resina $=14 \mathrm{mg} \mathrm{dm}^{-3}$; M.O. $=29$ mg dm${ }^{-3} ; \mathrm{pH} \mathrm{em} \mathrm{CaCl}_{2}=5,5 ; \mathrm{K}=2,4$ mmolc dm$^{-3} ; \mathrm{Ca}=25$ mmolc dm ${ }^{-3} ; \mathrm{Mg}=13 \mathrm{mmolc} \mathrm{dm}^{-3} ; \mathrm{H}+\mathrm{Al}=21 \mathrm{mmolc} \mathrm{dm}^{-3}$; $\mathrm{SB}=40 \mathrm{mmolc} \mathrm{dm}^{-3} ; \mathrm{CTC}=61 \mathrm{mmolc} \mathrm{dm}^{-3} ; \mathrm{V}=66 \%$. Não houve necessidade de realizar calagem.

A adubação de semeadura foi composta por: 80; 150; 20; 0,5; 1,00; 0,02 e 1,5 $\mathrm{mg} \mathrm{dm}^{-3}$ de P, K, S, B, Cu, Mo e Zn, respectivamente, por vaso. Utilizaram-se vasos de alumínio com capacidade para $3 \mathrm{dm}^{3}$, nos quais foram adicionados $2,8 \mathrm{dm}^{3}$ de solo. Após a aplicação dos nutrientes e das doses de N, foram semeadas dez sementes por vaso. Após a germinação, realizou-se o raleio de forma que apenas cinco plântulas permaneceram em cada vaso, constituindo uma unidade experimental.

Aos 25 dias após emergência (DAE), foram observados sintomas de deficiência de nitrogênio, caracterizados pelo amarelecimento das folhas mais velhas, principalmente nos tratamentos sem a aplicação de nitrogênio. Foi administrada uma adubação de cobertura com $50 \mathrm{mg}$ dm-3 de potássio aos $28 \mathrm{DAE}$, e aos $40 \mathrm{DAE}$, as plantas de sorgo foram colhidas e transportadas ao laboratório em embalagens plásticas, devidamente identificadas.

Realizaram-se leituras, por meio do medidor portátil de clorofila (SPAD), na quarta folha com bainha visível, na região mediana da folha de cada planta em todos os tratamentos. Foram realizadas três leituras com o medidor, das quais se obteve a média para cada folha amostrada por tratamento. Também foram determinados os teores de clorofilas a, b e total, segundo metodologia descrita por 
Hendry e Price ${ }^{12}$. Realizou-se a leitura das absorbâncias e os valores foram registrados nos comprimentos de onda de 645 e $663 \mathrm{~nm}$ para fins de obter as concentrações das clorofilas a, b e total.

O restante das plantas foram separadas em colmo + bainha e lâminas foliares, lavadas, colocadas para secar em estufa a $65^{\circ} \mathrm{C}$ e após pesagem obtiveram-se a produção de matéria seca e o teor de $\mathrm{N}$ total, de acordo com Bataglia ${ }^{13}$.

Os dados foram submetidos à análise de variância e, quando as médias apresentavam nível de significância, foram comparados pelo teste de Tukey a $5 \%$ de probabilidade e para as doses de $\mathrm{N}$ foram realizadas análises de regressão e submetidos à análise de correlação de Pearson para avaliar as variáveis estudadas.

\section{Resultados e Discussões}

Os resultados do teor de $\mathrm{N}$ na folha, concentração de clorofila a, b e total, produção de matéria seca e produção relativa encontram-se na Tabela 1 . De acordo com os valores encontrados, verificou-se aumento significativo no teor de nitrogênio nas folhas de sorgo com o aumento da dose de nitrogênio quando comparado à testemunha.

Em relação ao valor SPAD, não se verificou diferença significativa a partir da dose de $150 \mathrm{mg} \mathrm{dm}^{-3}$ de N. Os teores de clorofila a, b e total apresentaram comportamento semelhante entre os tratamentos, sendo que a dose de 300 $\mathrm{mg} \mathrm{g}^{-1}$ de $\mathrm{N}$ propiciou a extração das maiores quantidades, 1,27 e $1,12 \mathrm{mg} \mathrm{g}^{-1}$ de $\mathrm{N}$, respectivamente para a clorofila a e b. Houve aumento significativo para matéria seca até a dose de $225 \mathrm{mg} \mathrm{g}^{-1}$ de $\mathrm{N}$, na qual se obteve a maior produção relativa (100\%). Entretanto, quando foi aplicado a dose de $300 \mathrm{mg} \mathrm{g}^{-1}$ de $\mathrm{N}$, houve um decréscimo na produção (92\%). Tal fato indica que, a dose de $225 \mathrm{mg} \mathrm{g}^{-1}$ de $\mathrm{N}$ foi suficiente para maximizar o crescimento das plantas. Resultados diferentes aos encontrados por Oliveira ${ }^{14}$, os quais, analisando cultivares de sorgo e doses de nitrogênio , não observaram efeito significativo das doses de $\mathrm{N}$ sobre a produção de massa seca.

$\mathrm{O}$ fornecimento de nitrogênio em quantidades adequadas, além de incrementar a área foliar das plantas, aumenta os teores de clorofila nas folhas, tornando-as mais eficientes na interceptação da radiação solar ${ }^{2}$, refletindo, consequentemente, em maior acúmulo de matéria seca.

No desenvolvimento do experimento foi observado que no tratamento em que não foi adicionado nitrogênio houve um amarelecimento das folhas mais velhas, com as mais novas permanecendo verdes, este fato é um indicativo da mobilidade do nitrogênio na planta. As proteínas translocam-se das folhas deficientes e são reutilizadas nas folhas mais novas ${ }^{15}$.

A análise de correlação simples evidenciou uma alta correlação entre as leituras obtidas no medidor portátil, os teores de $\mathrm{N}$ e de clorofila e a produção de matéria seca, variando de 0,77 a 0,99 (Tabela 2). A alta correlação verificada entre a leitura com o medidor portátil de clorofila e o teor de clorofila total na folha $(0,95)$ evidencia que as leituras efetuadas com o medidor portátil estimam adequadamente o teor de clorofila da folha de sorgo.

$\mathrm{O}$ teor de clorofila na folha correlacionou-se positivamente com o teor de N no sorgo. Resultados obtidos

Tabela 1. Valores obtidos da leitura SPAD, teor de $\mathrm{N}$ e de clorofila na folha, matéria seca produzida e produção relativa na cultura do sorgo.

\begin{tabular}{|c|c|c|c|c|c|c|c|}
\hline \multirow{2}{*}{$\begin{array}{c}\text { Doses } \\
\text { de } N\end{array}$} & \multirow{2}{*}{$\begin{array}{c}\text { Leitura } \\
\text { SPAD }\end{array}$} & \multirow{2}{*}{$\begin{array}{l}\text { Teor de } \\
\text { N Foliar }\end{array}$} & \multicolumn{3}{|c|}{ Teor de Clorofila } & \multirow{2}{*}{$\begin{array}{c}\text { Matéria } \\
\text { Seca }\end{array}$} & \multirow{2}{*}{$\begin{array}{c}\text { Produção } \\
\text { Relativa }\end{array}$} \\
\hline & & & $\bar{a}$ & b & total & & \\
\hline$---\mathrm{mg} \mathrm{dm}{ }^{-3}---$ & --------- & $---\mathrm{g} \mathrm{kg}^{-1}---$ & \multicolumn{3}{|c|}{ 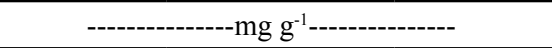 } & ----g---- & $--\%--$ \\
\hline 0 & $20,36 \mathrm{a}$ & $6,23 \mathrm{a}$ & $0,53 \mathrm{a}$ & $0,70 \mathrm{a}$ & $1,23 \mathrm{a}$ & 8,13 a & 37 \\
\hline 75 & $29,70 \mathrm{~b}$ & $9,85 \mathrm{~b}$ & $0,84 \mathrm{~b}$ & $0,95 \mathrm{ab}$ & $1,79 \mathrm{~b}$ & $17,86 \mathrm{~b}$ & 82 \\
\hline 150 & $30,09 \mathrm{c}$ & $11,53 \mathrm{c}$ & $0,90 \mathrm{bc}$ & $0,99 \mathrm{bc}$ & $1,89 \mathrm{ab}$ & $20,72 \mathrm{c}$ & 95 \\
\hline 225 & $34,51 \mathrm{c}$ & $13,88 \mathrm{~d}$ & $1,08 \mathrm{~cd}$ & $1,05 \mathrm{~cd}$ & $2,13 \mathrm{~cd}$ & $21,69 \mathrm{c}$ & 100 \\
\hline 300 & $35,19 \mathrm{c}$ & $17,55 \mathrm{e}$ & $1,27 \mathrm{~d}$ & $1,12 \mathrm{~d}$ & $2,39 \mathrm{~d}$ & $20,04 \mathrm{bc}$ & 92 \\
\hline CV $(\%)$ & 4,22 & 4,68 & 6,48 & 4,30 & 9,56 & 6,49 & --- \\
\hline DMS & 2,7629 & 1,2077 & 0,2665 & 0,090 & 0,1929 & 2,5069 & --- \\
\hline
\end{tabular}

Médias seguidas pela mesma letra na coluna, não diferem entre si pelo teste de Tukey a $5 \%$ de probabilidade. 
Tabela 2 - Correlações lineares de Pearson entre os parâmetros avaliados no experimento, com nível de significância de 5\% de probabilidade.

\begin{tabular}{|c|c|c|c|c|c|c|}
\hline Variáveis & $\begin{array}{c}\text { Leitura } \\
\text { SPAD }\end{array}$ & $\begin{array}{c}\text { Teor de } \\
\text { N na } \\
\text { folha }\end{array}$ & $\begin{array}{c}\text { Clorofila } \\
\text { total }\end{array}$ & \multicolumn{2}{|c|}{ Clorofila } & $\begin{array}{c}\text { Matéria } \\
\text { Seca }\end{array}$ \\
\hline $\begin{array}{c}\text { Leitura } \\
\text { SPAD }\end{array}$ & 1,00 & -- & -- & -- & -- & -- \\
\hline $\begin{array}{c}\text { Teor de N } \\
\text { na folha }\end{array}$ & $0,91^{*}$ & 1,00 & -- & -- & -- & -- \\
\hline $\begin{array}{c}\text { Clorofila } \\
\text { total }\end{array}$ & $0,95^{*}$ & $0,95^{*}$ & 1,00 & -- & -- & -- \\
\hline $\begin{array}{c}\text { Clorofila } \\
\text { a }\end{array}$ & $0,95^{*}$ & $0,92^{*}$ & $0,98^{*}$ & 1,00 & -- & -- \\
\hline $\begin{array}{c}\text { Clorofila } \\
\text { b }\end{array}$ & $0,93^{*}$ & $0,95^{*}$ & $0,99^{*}$ & $0,96^{*}$ & 1,00 & - \\
\hline $\begin{array}{c}\text { Matéria } \\
\text { Seca }\end{array}$ & $0,90^{*}$ & $0,77^{*}$ & $0,83^{*}$ & $0,88^{*}$ & $0,79 *$ & 1,00 \\
\hline
\end{tabular}

também por Schadchina ${ }^{16}$ e Waskom ${ }^{17}$. Para a clorofila total e para clorofila $\mathrm{b}$ foi de 0,95 , para clorofila a foi um pouco mais baixa de 0,92 . Esta relação é atribuída principalmente ao fato de 50 a $70 \%$ do $\mathrm{N}$ total das folhas ser integrante de enzimas $^{18}$ que estão associadas aos cloroplastos ${ }^{19}$.

A leitura com o medidor portátil apresenta algumas vantagens sobre o método de extração de clorofila: a leitura pode ser realizada em poucos minutos, não há necessidade de coleta e envio de amostras para o laboratório, com economia de tempo e dinheiro, é um método não destrutivo, no qual podem ser realizadas quantas amostras forem necessárias ${ }^{1}$. Portanto, as leituras efetuadas pelo equipamento podem substituir, com boa precisão, as determinações tradicionais do teor de clorofila. Avaliações realizadas em outras espécies ${ }^{20,21,22}$ também constataram relação significativa entre a leitura do medidor portátil e o teor de clorofila extraível.

A produção de matéria seca apresentou maior correlação com a leitura do medidor portátil $(0,90)$ do que com os outros parâmetros avaliados. Resultados diferentes dos encontrados por $\operatorname{Argenta}^{23}$, que não verificaram correlação na cultura do milho entre a leitura obtida no medidor portátil com a matéria seca. A maior limitação da utilização do medidor portátil de clorofila como indicador do teor do nitrogênio, é que ele não prediz com precisão a quantidade de $\mathrm{N}$ suplementar que deve ser aplicada ${ }^{17,24}$.

Nas Figuras 1 e 2 são apresentadas as curvas e respectivas equações que melhor ajustaram os valores obtidos pelo teor de $\mathrm{N}$ na folha, teor de clorofila (total, a e b), medidor portátil de clorofila (SPAD) e produção de matéria seca da folha em função da dose de $\mathrm{N}$ utilizada. Os teores de $\mathrm{N}$ total das folhas de sorgo assim como o teor das clorofilas total, a e b, cresceram linearmente com o aumento das doses de $\mathrm{N}$ (Figuras 1a e 1b).

As concentrações de $\mathrm{N}$ nas folhas se ajustaram linearmente de 6,22 a 17,55 $\mathrm{g} \mathrm{kg}^{-1}$ (Figura 1a). Na cultura do sorgo, os níveis adequados de nitrogênio nas folhas estão entre 13 a $15 \mathrm{~g} \mathrm{~kg}^{-1}$, segundo Malavolta ${ }^{1}$. No presente estudo verificou-se que quando foram utilizadas as doses de 225 e $300 \mathrm{mg} \mathrm{dm}^{-3}$, os teores de nitrogênio nas folhas obtidos foram respectivamente de 13,87 e $17,55 \mathrm{~g} \mathrm{~kg}^{-1}$, considerados adequados.

Para os teores de clorofila (a) os valores variaram

a)

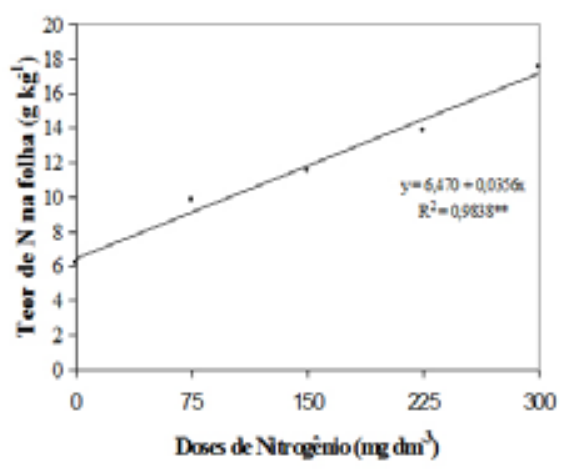

b)

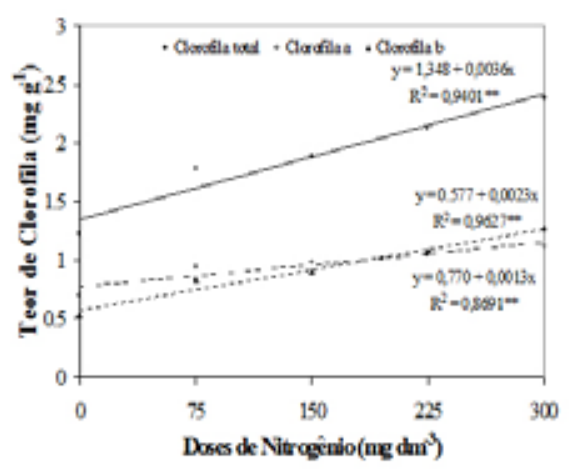

Figura 1 - Teor de nitrogênio nas folhas (a) e teor de clorofila a, b e total (b) em função de doses de nitrogênio na cultura do sorgo. 
de 0,69 a 1,11 mg g-1, para a clorofila (b) de 0,52 a $1,27 \mathrm{mg} \mathrm{g}^{-1}$ e para clorofila total de 1,22 a $2,38 \mathrm{mg}$ $\mathrm{g}^{-1}$ (Figura 1b). A análise regressão demonstrou que $\mathrm{o}$ valor obtido pelo medidor portátil de clorofila (Figura 2a) variou entre 20,35 e 35,18 unidades SPAD, em que se ajustaram a regressão quadrática com ponto de máximo de $241,5 \mathrm{mg} \mathrm{dm}^{-3} \mathrm{de} \mathrm{N}$, com coeficiente de determinação de 0,9367 .

Os valores da produção de matéria seca das folhas se ajustaram à regressão quadrática, com ponto de máximo de $218 \mathrm{mg} \mathrm{dm}^{-3}$ de $\mathrm{N}$, com o coeficiente de determinação de 0,9813 (Figura 2b). Aumentos da matéria seca, em função de doses crescentes de nitrogênio, foram verificados por Oliveira ${ }^{25}$. Isso pode estar relacionado com uma maior interceptação da radiação solar em virtude do aumento da área vegetativa das plantas e dos teores de clorofila existentes nas folhas ${ }^{26}$.

Assim, esse resultados indicam que, apesar dos teores de nitrogênio encontrados na planta com as doses de 225 e $300 \mathrm{mg} \mathrm{dm}^{-3}$ serem considerados suficientes para a cultura do sorgo, em relação à produção de matéria seca, a utilização de tais níveis propiciou um efeito depressivo na produção, atingindo seu máximo na dose de $218 \mathrm{mg}$ $\mathrm{dm}^{-3}$ (Figura 2b). Portanto, a utilização de doses maiores que $225 \mathrm{mg} \mathrm{dm}^{-3}$ causou queda da produção de matéria seca e gasto inútil com o nutriente.

Neste sentido, verificam-se poucos estudos, principalmente, recentes e enfocando à adubação nitrogenada e teores de clorofila na cultura do sorgo, sendo que os fatores como solo, condições climáticas, variedade, manejo do solo, principalmente adubação podem interferir no desenvolvimento da cultura.

\section{Conclusões}

O medidor portátil de clorofila (SPAD) apresentou alta correlação com os teores de nitrogênio total da planta, clorofila total, a e b, e produção de matéria seca, indicando ser um método rápido, prático e eficiente para se avaliar a concentração de clorofila.

As doses de 225 e $300 \mathrm{mg} \mathrm{dm}^{-3}$ de $\mathrm{N}$ proporcionaram teores foliares de 13,87 e 17,55 $\mathrm{g} \mathrm{kg}^{-1}$ considerados suficientes para a cultura do sorgo, entretanto, com essas doses verificou-se um efeito depressivo na produção de matéria seca. a)

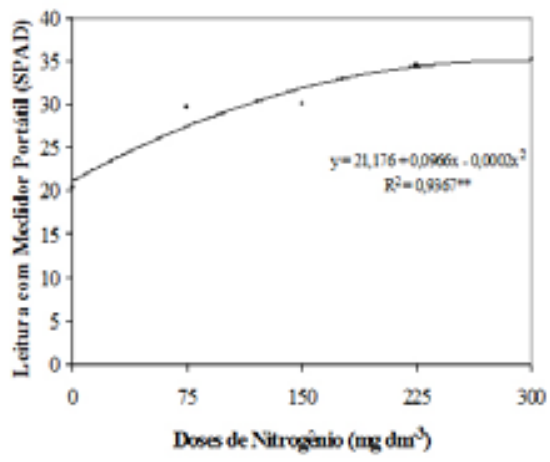

b)

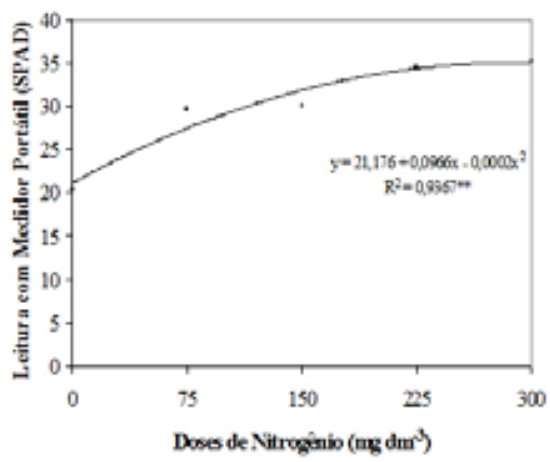

Figura 2 - Teor de clorofila determinada pelo medidor portátil de clorofila (SPAD) (a) e produção de matéria seca das folhas (b) em função de doses de nitrogênio na cultura do sorgo.

\section{Referências}

1. Malavolta, E.; Vitti, G. C.; Oliveira, S. A. Avaliação do estado nutricional das plantas: princípios e aplicações. Piracicaba, 1997. $317 \mathrm{p}$.

2. Taiz, L.; Zeiger, E. Plant physiology. 4. ed. Sunderland: Sinauer Associates, 2006. 705 p.

3. Evans, J. R. Oecologia, 1989, 78, 9-19.

4. Field, C.; Mooney, H. A. The photosynthesis nitrogen relationship in wild plants. University Press, Cambridge, 25-53, 1986.

5. Guimarães, T. G.; Fontes, P. C. R.; Pereira, P. R. G; Alvarez, V. H.; Monnerat, P. H. Bragantia, 1999, 58, 1, 209-216.

6. Argenta, G.; Silva, P. R. F.; Bortolini, C. G. Cienc. Rural, 2001, $31,4,715-722$.

7. Argenta, G.; Silva, P. R. F.; Bortolini, C. G.; Forsthofer, E. L.; Strider, M. L. Rev. Bras. Fisiol. Veg., 2001, 13, 2, 158-167.

8. Silveira, P. M.; Braz, A. J. B. P.; Didonet, A. D. Pesqui. Agropecu. Bras., 2003, 38, 1083-1087, 2003. 
9. Blackmer, T. M.; Schepers, J. S. Commun. Soil Sci. Plan., 1995, $25,1791-1800$.

10. Coelho, A. M. Diagnose foliar em milho e sorgo. In: Prado, R. M.; Rozane, D. E.; Vale, D. W.; Correia, M. A. R.; Souza, H. A. Nutrição de plantas diagnose foliar em grandes culturas. Jaboticabal: Capes/Fundunesp, p. 179-192, 2008.

11. Schepers, J. S.; Francis, D. D.; Pvcgil, M.; Below, F. E. Commun. Soil Sci. Plan., 1992, 23, 2173-2187.

12. Hendry, G. A. F.; Price, A. H. Stress indicators: cholorophylls and carotenoids. In: Hendry, G. A. F.; Grime, J. P. (Eds). Methods in comparative plant ecology. London, Chapman Hall, p. 148-152. 1993.

13. Bataglia, O. C.; Furlani, A. M. C.; Teixeira, J. P. F.; Furlani, P. R.; Gallo, J. R. Métodos de análise química de plantas. Campinas: Instituto Agronômico, 1983. 48p. (Boletim Técnico, 78).

14. Oliveira, R. P.; França, A. F. S.; Rodrigues Filho, O.; Oliveira, E. R.; Rosa, B.; Soares, T. V.; Mello, S. Q. S. Pesq. Agropec. Trop., 2005, 35, 1, 45-53.

15. Raij, B. van. Fertilidade do solo e adubação. Piracicaba: Ceres; Potafos, 1991. 343 p.

16. Schadchina, T. M.; Dmitrieva, V. V. J. Plant. Nut., 1995, 18, 6, 1427-1437.

17. Waskom, R. M.; Westfall, D. G.; Spellman, D. E.; Soltanpour, P. N. Commun. Soil Sci. Plan., 1996, 27, 3, 545-560.

18. Chapman, S. C.; Barreto, H. J. Agronomy J., 1997, 89, 4, $557-$ 562.

19. Stoking, C. R.; Ongun, A. Am. J. Bot., 1962, 49, 3, 284-289.

20. Dwyer, L. M.; Anderson, A. M.; Stewart, D. W.; Tollenaar, M.; Gregorich, E. Can. J. Plant. Sci., 1995, 75, 179-182.

21. Yadava, U. L. HortScience, 1986, 21, 1449-1450.
22. Tenga, A. Z.; Marie, B. A.; Ormrod, D. P. HortScience, 1989, 24, 514.

23. Argenta, G.; Silva, P. R. F.; Mielniczuk, J.; Bortolini, C. G. Pesqui. Agropecu. Bras., 2002, 37, 4, 519-527.

24. Sunderman, H. D.; Pontius, J. S.; Lawless, J. R. Commun. Soil Sci. Plan., 1997, 28, 19, 1793-1803.

25. Oliveira, P. R.; França, A. F. S.; Silva, A. G.; Miyagi, E. S.; Oliveira, E. R.; Perón, H. J. M. C. Cienc. Anim. Bras., 2009, 10, 4, 1003-1012.

26. Goes, R. J.; Rodrigues, R. A. F.; Arf, O.; Arruda, O. G.; Vilela, R. G. Rev. Bras. Milho e Sorgo, 2011, 10, 2, 121-129.

\section{Vitor C. M. Barretto ${ }^{*}$, Alex da Silva', José M. G. Beraldo², Mara C. P. $\mathrm{Cruz}^{3} \&$ Manoel E. Ferreira ${ }^{3}$}

${ }^{1}$ Universidade Estadual de Goiás, UEG, UnU Ipameri, Rodovia GO 330, Km 241, Anel Viário, CEP 75780-000, Ipameri, GO, Brasil.

${ }^{2}$ Instituto Federal de Educação, Ciência e Tecnologia de São Paulo, IFSP, CEP 15990-040, Matão, SP, Brasil.

${ }^{3}$ Universidade Estadual Paulista, Faculdade de Ciências Agrárias e Veterinárias, UNESP/FCAV, Departamento de Solos e Adubos, CEP 14884-900, Jaboticabal, SP, Brasil.

* e-mail: barrettovitor@yahoo.com.br 